\title{
The addition of bevacizumab in the first-line treatment for metastatic colorectal cancer: an updated meta-analysis of randomized trials
}

\author{
Hyun Joo Jang ${ }^{1}$, Bum Jun Kim ${ }^{2,3}$, Jung Han Kim² and Hyeong Su Kim² \\ ${ }^{1}$ Division of Gastroenterology, Department of Internal Medicine, Dongtan Sacred-Heart Hospital, Hallym University Medical \\ Center, Hallym University College of Medicine, Hwasung 18450, Republic of Korea \\ ${ }^{2}$ Division of Hemato-Oncology, Department of Internal Medicine, Kangnam Sacred-Heart Hospital, Hallym University Medical \\ Center, Hallym University College of Medicine, Seoul 07441, Republic of Korea \\ ${ }^{3}$ Department of Internal Medicine, Korean Armed Forces Capital Hospital, The Armed Forces Medical Command, Sungnam \\ 13574, Republic of Korea
}

Correspondence to: Jung Han Kim, email: harricil@hotmail.com Hyeong Su Kim, email: nep2n@hallym.or.kr

Keywords: colorectal cancer, bevacizumab, irinotecan, meta-analysis

Received: May 16, 2017 Accepted: August 06, $2017 \quad$ Published: August 17, 2017

Copyright: Jang et al. This is an open-access article distributed under the terms of the Creative Commons Attribution License 3.0 (CC BY 3.0), which permits unrestricted use, distribution, and reproduction in any medium, provided the original author and source are credited.

\section{ABSTRACT}

Bevacizumab has shown survival benefits when added to chemotherapy in patients with metastatic colon cancer ( $\mathrm{MCRC}$ ). However, the efficacy of bevacizumab may depend on the accompanying chemotherapeutic regimen. We performed this metaanalysis to examine the impact of the choice of chemotherapy regimen on the survival benefits of bevacizumab in the first-line treatment for patients with mCRC. Electric databases were searched for eligible randomized trials. From 9 studies, 3,710 patients with $\mathrm{MCRC}$ were included in the meta-analysis of hazard ratios (HRs) for progressionfree survival (PFS) or overall survival (OS). Compared with chemotherapy alone, the addition of bevacizumab to chemotherapy significantly prolonged PFS (HR $=0.66$ [95\% confidence interval (CI), 0.55-0.77], $P<0.0001)$ and OS (HR $=0.84$ [95\% CI, $0.77-0.92], P=0.0001)$. In the subgroup analysis according to the chemotherapeutic regimens, bevacizumab showed both PFS (HR $=0.57$ [95\% CI, 0.41-0.77], $P=0.0004)$ and OS (HR $=0.79[95 \% C I, 0.67-0.93], P=0.004)$ advantages only in combination with irinotecan-based regimen. In conclusion, this meta-analysis confirms that the addition of bevacizumab to chemotherapy significantly prolongs PFS and OS in the first-line treatment for MCRC. The subgroup analyses suggest that irinotecan-based regimen may be a better partner of bevacizumab in terms of both PFS and OS.

\section{INTRODUCTION}

Colorectal (CRC) is the third most common cancer and the second leading cause of cancer-related death worldwide $[1,2]$. Approximately $80 \%$ of patients with $\mathrm{CRC}$ have resectable disease at the time of diagnosis [3], but $30-50 \%$ of patients who undergo curative surgery experience disease recurrence and die of metastatic diseases [4]. Standard treatment for non-resectable metastatic CRC (mCRC) is combination chemotherapy with or without a targeted molecular agent.

For more than four decades, 5-fluorouracil (5-FU) plus leucovirin (LV) was the only approved regimen to treat mCRC, producing mild survival benefit over best supportive care [5-6]. In 1990s, the introduction of irinotecan or oxaliplatin into the 5-FU-based regimen led to a significant increase in overall response rate (ORR), progression-free survival (PFS), or overall survival (OS) [7-8]. Capecitabine, an oral fluoropyrimidine, has been proved as an effective alternative to 5 -FU in mCRC [9]. Since 2000, the addition of targeted agents such as bevacizumab, cetuximab, or panitumumab to standard chemotherapy has broadened treatment options with an additional survival benefits [10-19]. In clinical practice, various chemotherapy regimens [bolus 5-FU/LV (FL), capecitabine monotherapy, irinotecan plus bolus 5-FU/ 
LV (IFL), irinotecan plus infusional 5-FU/LV (FOLFIRI), oxaliplatin plus infusional 5-FU/LV (FOLFOX), capecitabine plus oxaliplatin (XELOX)] can be used in combination with a targeted agent.

Cetuximab, a monoclonal antibody against epidermal growth factor receptor, has demonstrated its survival benefit in the first-line treatment for patients with $K R A S$ wild-type mCRC $[10,11]$. However, a recent metaanalysis of four randomized trials found that only patients treated with infusional 5-FU-based chemotherapy, not those with capecitabine/bolus 5-FU-based chemotherapy, derived benefit from cetuximab [20]. This finding suggests that the efficacy of cetuximab may depend on the choice and schedule of fluoropyrimidine.

Bevacizuamb is a humanized recombinant monoclonal antibody that blocks all isoforms of vascular endothelial growth factor-A. Several randomized clinical trials in patients with $\mathrm{mCRC}$ have demonstrated that bevacizumab in combination with chemotherapy improves PFS or OS [13-19]. However, the impact of the choice of accompanying chemotherapeutic regimen on the benefit of bevacizumab has not been revealed. In a randomized phase III trial with a $2 \times 2$ factorial design, statistical PFS superiority of bevacizumab versus placebo was evident in the XELOX subgroup [hazard ration $(\mathrm{HR})=0.77$, $P=0.0026]$, but did not reach the significance level in the infusional 5-FU/LV plus oxaliplatin (FOLFOX-4) subgroup $(\mathrm{HR}=0.89, P=0.1871)$ [13]. Thus, the efficacy of bevacizumab might depend on the cytotoxic drugs combined. We performed this meta-analysis of randomized controlled trials to examine the impact of the choice of chemotherapy regimen on the effect of bevacizumab in the first-line treatment for patients with $\mathrm{mCRC}$.

\section{RESULTS}

\section{Results of search}

Figure 1 shows the search process based on the applied keywords and inclusion criteria. A total of 496 potentially relevant studies were identified and screened by the search strategy; 476 were excluded after screening the titles and abstracts. Of the remaining 20 prospective studies, eleven were further excluded by the inclusion criteria: six prospective trials with no chemotherapy only control arm, three evaluating chemotherapy plus bevacizumab as adjuvant treatment, one conducted in second-line setting, and the remaining one nonrandomized phase II trial. Finally, nine randomized phase II or III trials were included in this meta-analysis [13-19, $21,22]$.

\section{Characteristics of the eligible studies}

Table 1 shows the main characteristics and outcomes of the included randomized trials. We also summarized treatment regimens used in each arm. Seven phase III trials [14, 16-19, 21, 22] and two phase II trials [13, 15] were included. In most studies except for three $[15,16$, 21], the primary endpoint was PFS.

\section{Progression-free survival}

From the nine studies [13-19, 21, 22], a total of 3,710 patients $(1,822$ in chemotherapy alone group and 1,888 in bevacizumab plus chemotherapy group) were included in the meta-analysis of HRs for PFS. Compared

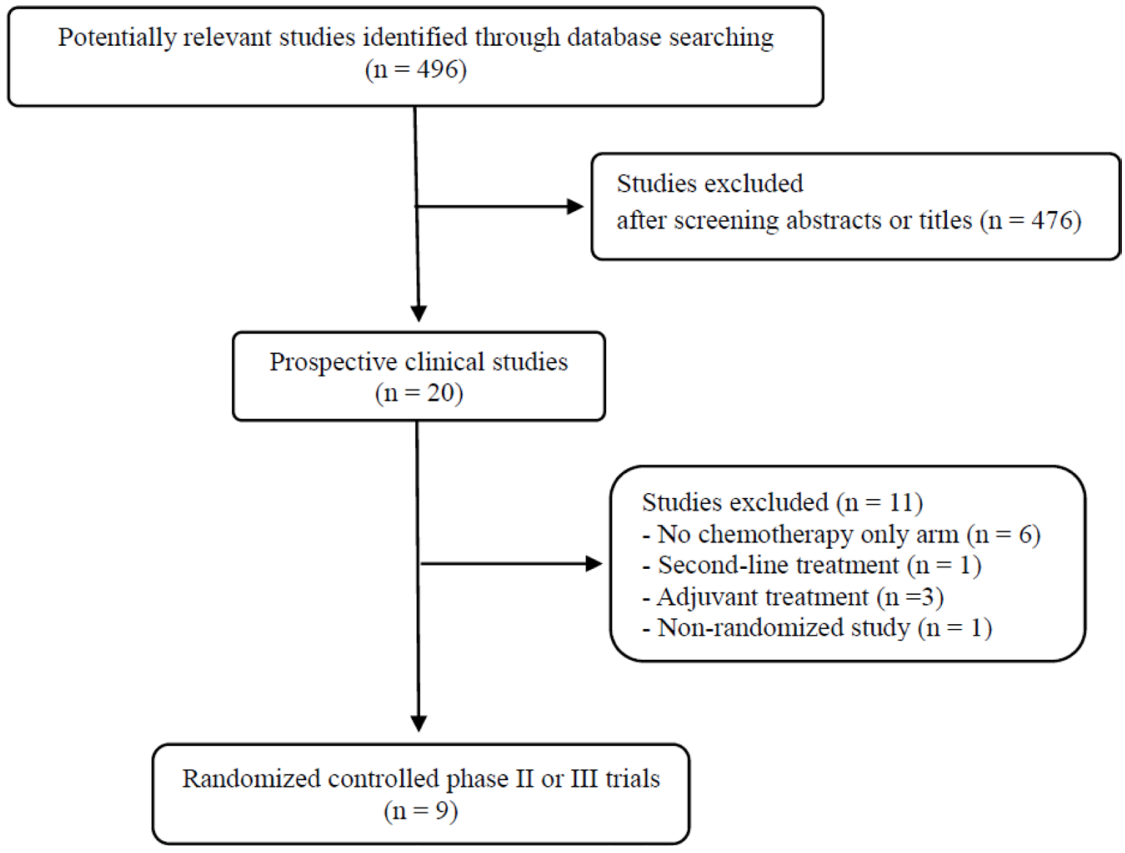

Figure 1: Flow diagram of search process. 
Table 1: Summary of the nine included studies

\begin{tabular}{|c|c|c|c|c|c|c|c|c|c|}
\hline $\begin{array}{l}\text { Author, } \\
\text { (year) }\end{array}$ & Phase & $\begin{array}{l}\text { No. of } \\
\text { patients }\end{array}$ & Treatment arms & $\begin{array}{l}\text { Primary } \\
\text { endpoint }\end{array}$ & ORR & $\begin{array}{l}\mathrm{mPFS} \\
(\mathrm{mo})\end{array}$ & $\begin{array}{l}\text { HR for PFS } \\
(95 \% \mathrm{CI})\end{array}$ & $\begin{array}{l}\mathrm{mOS} \\
(\mathrm{mo})\end{array}$ & $\begin{array}{l}\text { HR for OS } \\
(95 \% \mathrm{CI})\end{array}$ \\
\hline \multirow[t]{3}{*}{$\begin{array}{l}\text { Kabbinavar et al., } \\
(2003)\end{array}$} & II & 36 & $\begin{array}{l}\text { Bolus } 5 \text {-FU } 500 \mathrm{mg} / \mathrm{m}^{2}+\mathrm{LV} 500 \mathrm{mg} / \mathrm{m}^{2} \text { wkly for } \\
\text { the first } 6 \text { wks of each } 8 \text {-wk cycle. }\end{array}$ & $\begin{array}{l}\text { ORR } \\
\text { PFS }\end{array}$ & $17 \%$ & 5.2 & $\begin{array}{l}0.54(0.33-0.88) \\
(\mathrm{FL} \pm \mathrm{Bev}) \\
P=0.003\end{array}$ & 13.8 & na \\
\hline & & 35 & Same with bevacizumab $5 \mathrm{mg} / \mathrm{kg}$ every $2 \mathrm{wk}$ & & $40 \%$ & 9.0 & & 21.5 & \\
\hline & & 33 & Same with bevacizumab $10 \mathrm{mg} / \mathrm{kg}$ every $2 \mathrm{wk}$ & & $24 \%$ & 7.2 & & 16.1 & \\
\hline \multirow[t]{2}{*}{$\begin{array}{l}\text { Hurwitz et al., } \\
(2004)\end{array}$} & III & 411 & $\begin{array}{l}\text { Irinotecan } 125 \mathrm{mg} / \mathrm{m}^{2}+\text { bolus } 5 \text {-FU } 500 \mathrm{mg} / \mathrm{m}^{2+} \\
\mathrm{LV} 20 \mathrm{mg} / \mathrm{m}^{2} \text { once wkly for } 4 \text { wk every } 6 \mathrm{wk}\end{array}$ & OS & $34.8 \%$ & 6.2 & $\begin{array}{l}0.54(0.37-0.78) \\
P<0.001\end{array}$ & 15.6 & $\begin{array}{l}0.66(0.52-0.85) \\
P<0.001\end{array}$ \\
\hline & & 402 & Same with bevacizumab $5 \mathrm{mg} / \mathrm{kg}$ every $2 \mathrm{wk}$ & & $44.8 \%$ & 10.6 & & 20.3 & \\
\hline \multirow[t]{2}{*}{$\begin{array}{l}\text { Kabbinavar et al., } \\
(2005)\end{array}$} & II & 105 & $\begin{array}{l}\text { Bolus } 5 \text {-FU } 500 \mathrm{mg} / \mathrm{m}^{2}+\mathrm{LV} 500 \mathrm{mg} / \mathrm{m}^{2} \text { wkly for } \\
\text { the first } 6 \text { wk of each } 8 \text {-wk cycle. }\end{array}$ & OS & $15.2 \%$ & 5.5 & $\begin{array}{l}0.50(0.34-0.74) \\
P=0.0002\end{array}$ & 12.9 & $\begin{array}{l}0.78(0.56-1.10) \\
P=0.16\end{array}$ \\
\hline & & 104 & Same with bevacizumab $5 \mathrm{mg} / \mathrm{kg}$ every $2 \mathrm{wk}$ & & $26.0 \%$ & 9.2 & & 16.6 & \\
\hline \multirow{2}{*}{$\begin{array}{l}\text { Stathopoulos } \\
\text { et al., } \\
(2010)\end{array}$} & III & 108 & $\begin{array}{l}\text { Bolus 5-FU } 500 \mathrm{mg} / \mathrm{m}^{2}+\mathrm{LV} 200 \mathrm{mg} / \mathrm{m}^{2} \text { with } \\
\text { irinotecan } 135 \mathrm{mg} / \mathrm{m}^{2} \text { every } 3 \mathrm{wk}\end{array}$ & OS & $35.2 \%$ & na & na & 25 & $\begin{array}{l}1.05(0.81-1.36) \\
P=0.139\end{array}$ \\
\hline & & 114 & Same with bevacizumab $7.5 \mathrm{mg} / \mathrm{kg}$ every $3 \mathrm{wk}$ & & $36.8 \%$ & na & & 22 & \\
\hline \multirow[t]{2}{*}{$\begin{array}{l}\text { Saltz et al., } \\
\text { (2008) }\end{array}$} & III & $\begin{array}{l}701 \\
(350 / 351)\end{array}$ & $\begin{array}{l}\text { XELOX (capecitabine } 1000 \mathrm{mg} / \mathrm{m}^{2} \text { twice daily } \\
\text { on days } 1-14+\text { oxaliplatin } 130 \mathrm{mg} / \mathrm{m}^{2} \text { on day } 1 \\
\text { every } 3 \mathrm{wk} \text { ) } \\
\text { or } \\
\text { FOLFOX-4 (oxaliplatin } 85 \mathrm{mg} / \mathrm{m}^{2} \text { on day } 1 \text { with } \\
\text { LV } 200 \mathrm{mg} / \mathrm{m}^{2} \text { followed by } 5-\mathrm{FU} \text { bolus } 400 \mathrm{mg} / \\
\mathrm{m}^{2} \text { and } 600 \mathrm{mg} / \mathrm{m}^{2} 22 \text {-h iv infusion for } 2 \text { days } \\
\text { every } 2 \mathrm{wk} \text { ) }\end{array}$ & PFS & $47 \%$ & 8.0 & $\begin{array}{l}0.83(0.74-0.93) \\
(\mathrm{Ctx} \pm \mathrm{Bev}) \\
P=0.0023 \\
\text { *XELOX } \pm \mathrm{Bev}: \\
0.77(0.65-0.92) \\
P=0.0026 \\
\text { *FOLFOX } 4 \pm \mathrm{Bev}: \\
0.89(0.74-1.06) \\
P=0.1871\end{array}$ & 19.9 & $\begin{array}{l}0.89(0.79-1.00) \\
(\mathrm{Ctx} \pm \mathrm{Bev}) \\
P=0.077 \\
\text { *XELOX } \pm \text { Bev: } \\
0.84(0.71-1.01) \\
\text { *FOLFOX-4 } \pm \text { Bev: } \\
0.94(0.77-1.15)\end{array}$ \\
\hline & & $\begin{array}{l}699 \\
(350 / 349)\end{array}$ & $\begin{array}{l}\text { XELOX + bevacizumab } 7.5 \mathrm{mg} / \mathrm{kg} \text { every } 3 \mathrm{wk} \\
\text { or } \\
\text { FOLFOX-4 + bevacizuamb } 5 \mathrm{mg} / \mathrm{kg} \text { every } 2 \mathrm{wk}\end{array}$ & & $49 \%$ & 9.4 & & 21.3 & \\
\hline \multirow[t]{3}{*}{$\begin{array}{l}\text { Tebutt et al., } \\
(2010)\end{array}$} & III & 156 & $\begin{array}{l}\text { Capecitabine } 1000 \text { or } 1250 \mathrm{mg} / \mathrm{m}^{2} \text { twice daily on } \\
\text { days } 1-14 \text { every } 3 \mathrm{wk}\end{array}$ & PFS & $30.3 \%$ & 5.7 & $\begin{array}{l}0.61(0.50-0.74) \\
(\mathrm{C} / \mathrm{CM} \pm \mathrm{Bev})\end{array}$ & 18.9 & na \\
\hline & & 157 & $\begin{array}{l}\text { Capecitabine (same) + bevacizumab } 7.5 \mathrm{mg} / \mathrm{kg} \\
\text { every } 3 \mathrm{wk}\end{array}$ & & $38.1 \%$ & 8.5 & $\begin{array}{l}0.62(0.49-0.79) \\
(\mathrm{C} \pm \mathrm{Bev}) \\
P<0.001\end{array}$ & 18.9 & $\begin{array}{l}0.88(0.68-1.13) \\
(\mathrm{C} \pm \mathrm{Bev}) \\
P=0.314\end{array}$ \\
\hline & & 158 & $\begin{array}{l}\text { Capecitabine (same) }+ \text { mitomycin } 7 \mathrm{mg} / \mathrm{m}^{2} \text { every } 6 \\
\text { wks+ bevacizumab } 7.5 \mathrm{mg} / \mathrm{kg} \text { every } 3 \mathrm{wk}\end{array}$ & & $45.9 \%$ & 8.4 & $\begin{array}{l}0.56(0.44-0.71) \\
(\mathrm{C} \text { vs CM }+ \text { Bev }) \\
P<0.001\end{array}$ & 16.4 & $\begin{array}{l}0.94(0.73-1.21) \\
(\mathrm{C} \text { vs CM }+ \text { Bev }) \\
P=0.642\end{array}$ \\
\hline \multirow{2}{*}{$\begin{array}{l}\text { Cunningham et } \\
\text { al., } \\
\text { (2013) }\end{array}$} & III & 140 & $\begin{array}{l}\text { Capecitabine } 1000 \mathrm{mg} / \mathrm{m}^{2} \text { twice daily on days } \\
1-14 \text {, every } 3 \mathrm{wk}\end{array}$ & PFS & $10 \%$ & 5.1 & $\begin{array}{l}0.53(0.41-0.69) \\
P<0.0001\end{array}$ & 16.8 & $\begin{array}{l}0.79(0.57-1.09) \\
P=0.18\end{array}$ \\
\hline & & 140 & $\begin{array}{l}\text { Same with bevacizumab } 7.5 \mathrm{mg} / \mathrm{kg} \text { on day } 1 \text { every } \\
3 \mathrm{wk}\end{array}$ & & $19 \%$ & 9.1 & & 20.7 & \\
\hline \multirow[t]{2}{*}{$\begin{array}{l}\text { Guan et al., } \\
\text { (2011) }\end{array}$} & III & 79 & $\begin{array}{l}\text { Irinotecan } 125 \mathrm{mg} / \mathrm{m}^{2}+\text { bolus LV } 20 \mathrm{mg} / \mathrm{m}^{2} \text { and } \\
5 \text {-FU } 500 \mathrm{mg} / \mathrm{m}^{2} \text { iv infusion over } 6-8 \mathrm{~h} \text { wkly for } 4 \\
\text { wk every } 6 \mathrm{wk}\end{array}$ & PFS & $17 \%$ & 4.2 & $\begin{array}{l}0.44(0.31-0.63) \\
P<0.001\end{array}$ & 13.4 & $\begin{array}{l}0.62(0.41-0.95) \\
P=0.014\end{array}$ \\
\hline & & 142 & Same with bevacizumab $5 \mathrm{mg} / \mathrm{kg}$ every $2 \mathrm{wk}$ & & $35 \%$ & 8.3 & & 18.7 & \\
\hline \multirow[t]{2}{*}{$\begin{array}{l}\text { Passardi et al., } \\
\text { (2015) }\end{array}$} & III & $\begin{array}{l}194 \\
(76 / 118)\end{array}$ & $\begin{array}{l}\text { FOLFIRI (irinotecan } 180 \mathrm{mg} / \mathrm{m}^{2} \text { on day } 1 \text { with } \\
5 \text {-FU } 400 \mathrm{mg} / \mathrm{m}^{2} \text { bolus and } 600 \mathrm{mg} / \mathrm{m}^{2} \text { by } 22 \text {-h } \\
\text { infusion }+\mathrm{LV} 200 \mathrm{mg} / \mathrm{m}^{2} \text { on days } 1 \text { and } 2 \text { every } \\
2 \text { wk) } \\
\text { or FOLFOX-4 }\end{array}$ & PFS & $50 \%$ & 8.4 & $\begin{array}{l}0.86(0.70-1.07) \\
P=0.182 \\
\text { *FOLFIRI } \pm \mathrm{Bev}: \\
0.75(0.54-1.05) \\
\text { *FOLFOX4 } \pm \mathrm{Bev}: \\
1.00(0.76-1.33)\end{array}$ & 21.3 & $\begin{array}{l}1.13(0.89-1.43) \\
P=0.317 \\
{ }^{*} \text { FOLFIRI } \pm \text { Bev: } \\
\text { na } \\
{ }^{*} \text { FOLFOX } 4 \pm \text { Bev: } \\
\text { na }\end{array}$ \\
\hline & & $\begin{array}{l}176 \\
(73 / 103)\end{array}$ & $\begin{array}{l}\text { FOLFIRI or } \\
\text { FOLFOX-4 with bevacizumab } 5 \mathrm{mg} / \mathrm{kg} \text { every } 2 \mathrm{wk}\end{array}$ & & $50.6 \%$ & 9.6 & & 20.8 & \\
\hline
\end{tabular}

Bev, bevacizumab; C, capecitabine; M, mitomycin; Ctx, chemotherapy; 5-FU, 5-fluorouracil; LV, leucovorin; FL, 5-fluorouracil plus leucovorin; ORR, overall response rate; CI, confidence interval; mOS, median overall survival; mPFS, median progression-free survival; HR, hazard ratio; wk, week; na, not available.

with chemotherapy alone, bevacizumab combined with chemotherapy significantly prolonged PFS $(\mathrm{HR}=0.66$ [95\% confidence interval (CI), 0.55-0.77], $P<0.0001$ ) (Figure 2). We adopted the random-effects model because there was a significant heterogeneity among studies $\left(X^{2}=\right.$ $32.19, P=0.0002, I^{2}=72 \%$ ).

In the subgroup analysis according to the chemotherapy regimens in combination with bevacizumab,
FL (HR $=0.52[95 \% \mathrm{CI}, 0.38-0.70], P<0.0001), \mathrm{IFL} /$ FOLFIRI (HR $=0.57$ [95\% CI, 0.41-0.77], $P=0.0004$ ), capecitabine (HR $=0.58$ [95\% CI, 0.48-0.69], $P<0.00001$ ), and XELOX (HR $=0.77$ [95\% CI, 0.65-0.92], $P=0.003$ ) were associated with a significant improvement of PFS. However, bevacizumab in combination with FOLFOX regimen failed to significantly prolong PFS, compared with FOLFOX alone (HR $=0.92$ [95\% CI, 0.79-1.07], $P=0.29)$. 


\section{Overall survival}

From the nine studies $[13-19,21,22]$, a total of 3,458 patients $(1,700$ in chemotherapy alone group and 1,758 in bevacizumab plus chemotherapy group) were included in the meta-analysis of HRs for OS. Compared with chemotherapy alone, the addition of bevacizumab to chemotherapy also significantly prolonged $\mathrm{OS}(\mathrm{HR}=0.84$ [95\% CI, 0.77-0.92], $P=0.0001$ ) (Figure 3). We adopted the fixed-effects model because there was no significant heterogeneity among studies $\left(X^{2}=10.21, P=0.18\right.$, $\left.I^{2}=31 \%\right)$.

In the subgroup analysis according to the chemotherapy regimens, FL (HR $=0.78[95 \%$ CI $0.56-$ 1.09 ], $P=0.15$ ), capecitabine (HR $=0.84$ [95\% CI, 0.69 1.03], $P=0.10)$, and FOLFOX regimen ( $\mathrm{HR}=0.94[95 \%$ CI, $0.77-1.15], P=0.55$ ) failed to significantly prolong OS in combination with bevacizumab. Compared with chemotherapy alone, however, IFL/FOLFIRI regimen combined with bevacizumab significantly prolonged OS (HR $=0.79$ [95\% CI, 0.67-0.93], $P=0.004)$ and XELOX plus bevacizumab tended to improve OS $(\mathrm{HR}=0.84[95 \%$ CI, 0.70-1.00], $P=0.05$ ).

\section{Publication bias}

The funnel plots are relatively symmetrical for both PFS and OS, indicating that the amount of publication bias in our meta-analysis is not substantial (Figure 4).

\section{DISCUSSION}

Bevacizumab has been tested alongside various chemotherapy regimens in patient with mCRC [13-19, $21,22]$. While many studies have shown that the addition of bevacizumab to chemotherapy significantly prolongs PFS or OS [13-19], other studies have not confirmed their findings $[22,23]$. The additional effect of bevacizumab on survival (PFS or OS) in patients with mCRC has been investigated in several meta-analyses [23-29]. Most studies indicated that the addition of bevacizumab to chemotherapy significantly prolonged both PFS and OS. In the subgroup analyses according to the involved chemotherapeutic agents, however, the survival benefits of bevacizumab were not in concordance among studies. These previous meta-analyses included a limited number of studies and adopted heterogeneous inclusion criteria (including non-randomized studies or studies with different treatment setting). Thus, we performed the current updated meta-analysis only with randomized controlled trials conducted in first-line treatment setting of mCRC. We also assessed the survival benefits of bevacizumab stratified by the choice of chemotherapeutic regimen, not according to the individual cytotoxic agents.

In our meta-analysis, chemotherapy combined with bevacizumab significantly prolonged PFS (HR $=0.66$, $P<0.0001)$ compared with chemotherapy alone. The addition of bevacizumab to chemotherapy also significantly improved OS (HR $=0.84, P=0.0001)$.

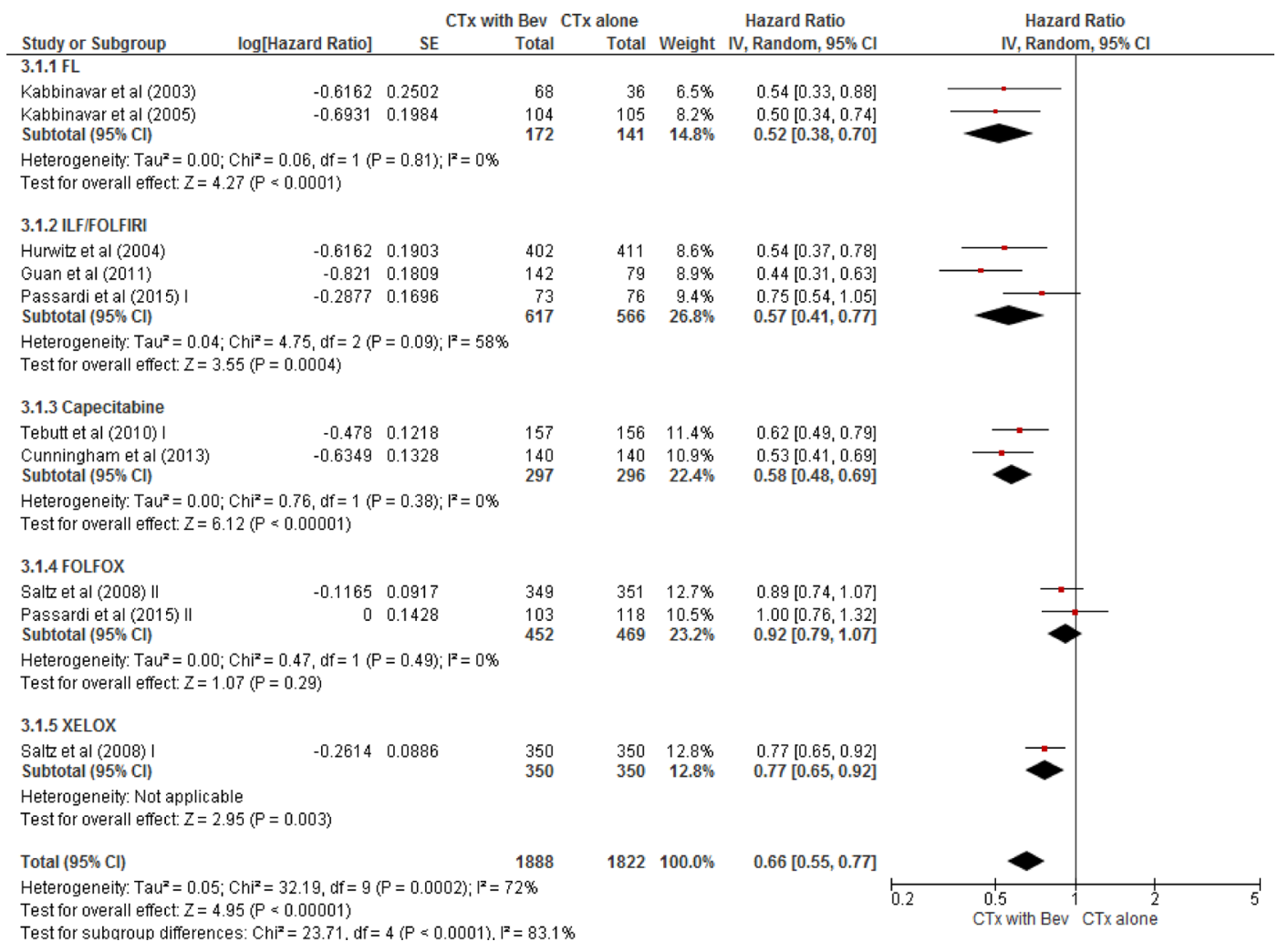

Figure 2: Forest plot for progression-free survival. 
Our results confirm the beneficial effects of adding bevacizumab to chemotherapy in terms of both PFS and OS. However, the survival benefits of bevacizumab were not consistent throughout the combined chemotherapeutic regimens. In the subgroup analysis, bevacizumab significantly improved both PFS $(\mathrm{HR}=0.57, P=0.0004)$ and $\mathrm{OS}(\mathrm{HR}=0.79, P=0.004)$ only in combination with irinotecan-based regimens (ILF or FOLFIRI).

In a previous meta-analysis by Chen et al., the addition of bevacizumab to the usual chemotherapy regimens significantly improved PFS $(\mathrm{HR}=0.68[95 \%$
CI, 0.59-0.78], $P<0.00001)$, but not OS (HR $=8.89$ [95\% CI, 0.78-1.02], $P=0.08$ ) [28]. In the subgroup analysis, the PFS benefit of bevacizumab was only observed when capecitabine-containing regimens were used. These findings may be due to insufficient data available at the time of meta-analysis. Recently Iliac et al. also published a meta-analysis in which a significant improvement was identified for both PFS (HR $=0.64$ [95\% CI, 0.55-0.73], $P<0.00001)$ and OS $(\mathrm{HR}=0.84$ [95\% CI, 0.74-0.94], $P=0.003$ ) when bevacizumab was combined with chemotherapy in patients with mCRC [29].

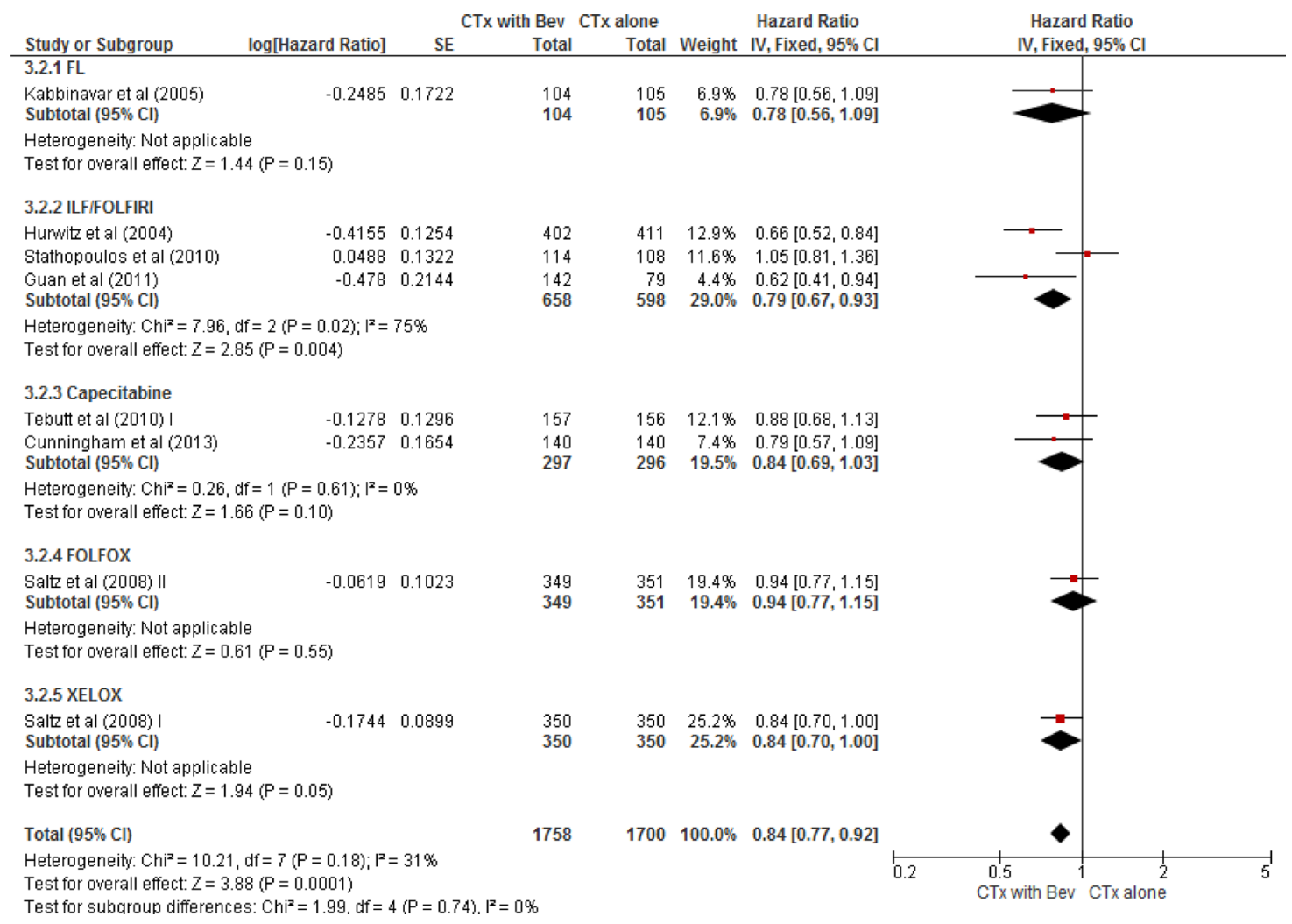

Figure 3: Forest plot for overall survival.
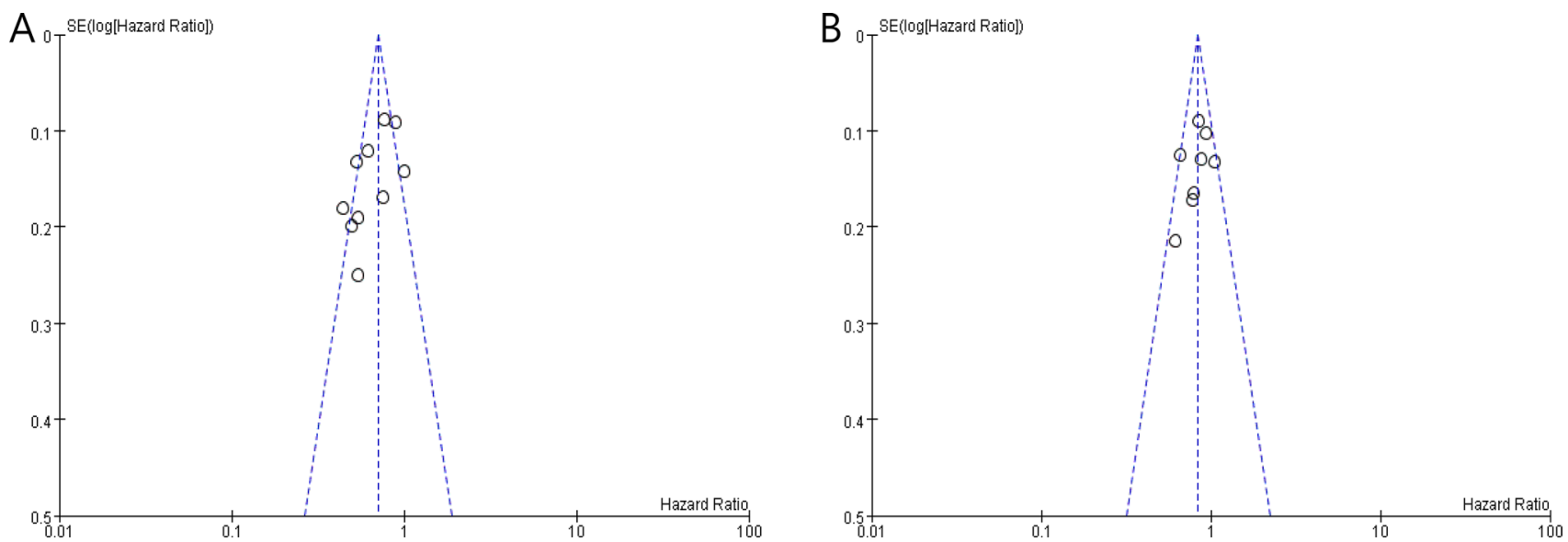

Figure 4: Funnel plots for publication bias test regarding progression-free survival (A) and overall survival (B). 
The subgroup analysis showed that the OS advantage was significant only for FL and oxalipatin-based regimens while the improvement of PFS remained throughout different chemotherapy regimens. However, this study included a non-randomized trial [30] and a randomized trial conducted in second-line setting [31].

Another meta-analysis by Macedo et al. found that bevacizumab significantly improved PFS $(\mathrm{HR}=0.72$, [95\% CI, 0.66-0.78], $P<0.000001)$ and OS (HR $=0.84$ [95\% CI, 0.77-0.91], $P<0.00001)$ in combination with chemotherapy. This study included 6 randomized trials only conducted in first-line treatment setting of mCRC. Subgroup analyses supported the OS advantage with bevacizumab restricted to irinotecan-based regimens, which are consistent with our results. These findings suggest that irinotecan-based regimens might be a better partner of bevacizumab in terms of both PFS and OS. However, these meta-analyses have a limited number of trials in each subgroup, and OS can be affected by therapies following first-line treatment. Thus, further researches are needed to reveal the interaction of bevacizuamb and cytotoxic agents and identify the best chemotherapeutic regimen which can derive the most benefits in combination with bevacizumab.

Of note, our study has several limitations. First, the subgroup analyses stratified by chemotherapeutic regimens included a limited number of studies in each subgroup. Therefore, our findings need to be verified in further studies. Second, there was a significant heterogeneity observed among studies especially in the meta-analysis of PFS. We used the random-effects model to minimize its influence on the results. Finally, literature search only included studies written in English, which might lead to omitting studies published in another language.

In conclusion, this meta-analysis confirms that the addition of bevacizumab to chemotherapy significantly prolongs PFS and OS in the first-line treatment for patients with mCRC. The subgroup analyses suggest that irinotecan-based regimen (ILF or FOLFIRI) might be a better partner of bevacizumab in terms of both PFS and OS. Considering that a limited number of trials were included in this meta-analysis, however, further studies are warranted to explore the best chemotherapeutic combination with bevacizumab.

\section{MATERIALS AND METHODS}

\section{Search strategy}

A systematic review of the literature was carried out according to the predefined protocol [32]. Electric databases including PubMed, EMBASE, and Cochrane Library databases were searched up to the end of April 2017 for eligible articles. The following searching keywords were used: "vascular endothelial growth factor inhibitor or bevacizumab", "colon cancer or colon neoplasm or colorectal cancer", and "randomized." All eligible studies were retrieved and their bibliographies were checked for other relevant publications. In case of duplicate publications, the most recent articles were selected.

\section{Study eligibility criteria}

Eligible studies were required to meet the following inclusion criteria: (i) randomized trials conducted in patients with $\mathrm{mCRC}$; (ii) randomization of patients in the first-line treatment setting to either chemotherapy alone or chemotherapy with becacizumab; (iii) providing HRs with 95\% CIs for PFS or OS; (iv) papers written in English.

Case series, observational studies, and trials conducted in adjuvant or second-line setting were excluded.

\section{Data extraction}

The following data were carefully extracted from all eligible studies: first author's name, year of publication, trial phase, the number of participants, treatment regimens, primary endpoints, overall response rates, median PFS and OS, and their HRs with 95\% CIs.

Data extraction was done independently by two investigators (HSK and HJJ). If these two authors could not reach a consensus, other author (JHK) was consulted to resolve the disputes.

\section{Statistical analysis}

Most statistical values used in this meta-analysis were collected directly from the original article. For papers with no HR or $95 \%$ CI, the Engauge Digitizer (version 9.1) was used to obtain the needed data from Kaplan-Meier curves. The effect size of PFS and OS was pooled through $\mathrm{HR}$ and its $95 \% \mathrm{CI}$. The heterogeneity across studies was examined by the $Q$ statistic and the $I^{2}$ statistic. The fixedeffects model (Mantel-Haenszel method) was selected for pooling the homogeneous outcomes when $P \geq 0.1$ and $I^{2} \leq$ $50 \%$, and the random-effects model (DerSimonian-Laird method) was applied for pooling heterogeneous outcomes when $P<0.1$ and $I^{2}>50 \%$.

All reported $P$-values were from two-sided versions of the respective test; $P<0.05$ was considered statistically significant. Results were presented graphically as forest plots with diamonds representing estimate of the polled effect and the width of diamond representing its precision. The Review Manager software (version 5.2) was used to report outcomes. Publication bias was assessed graphically by the funnel plot method [33].

\section{ACKNOWLEDGMENTS AND FUNDING}

This work had no specific funding support. 


\section{CONFLICTS OF INTEREST}

All authors have declared no competing interest.

\section{REFERENCES}

1. Ferlay J, Soerjomataram I, Dikshit R, Eser S, Mathers C, Rebelo M, Parkin DM, Forman D, Bray F. Cancer incidence and mortality worldwide: sources, methods and major patterns in GLOBOCAN 2012. Int J Cancer. 2015; 136:359-86.

2. Jung KW, Won YJ, Oh CM, Kong HJ, Lee DH, Lee KH. Community of Population-Based Regional Cancer Registries. Cancer statistics in Korea: incidence, mortality, survival, and prevalence in 2014. Cancer Res Treat. 2017; 49:292-305

3. Siegel RL, Miller KD, Jemal A. Cancer statistics, 2016. CA Cancer J Clin. 2016; 66:7-30.

4. Quasar Collaborative Group, Gray R, Barnwell J, McConkey C, Hills RK, Williams NS, Kerr DJ. Adjuvant chemotherapy versus observation in patients with colorectal cancer: a randomised study. Lancet. 2007; 370:2020-9.

5. Thrion P, Michiels S, Pignon JP, Buyse M, Braud AC, Carlson RW, O'Connell M, Sargent P, Piedbois P, MetaAnalysis Group in Cancer. Modulation of fluorouracil by leucovorin in patients with advanced colorectal cancer: An updated meta-analysis. J Clin Oncol. 2004; 22:3766-75.

6. de Gramont A, Figer A, Seymour M, Homerin M, Hmissi A, Cassidy J, Boni C, Cortes-Funes H, Cervantes A, Freyer G, Papamichael D, Le Bail N, Louvet C, et al. Leucovorin and fluorouracil with or without oxaliplatin as first-line treatment in advanced colorectal cancer. J Clin Oncol. 2000; 18: 2938-47.

7. Giacchetti S, Perpoint B, Zidani R, Le Bail N, Faggiuolo R, Focan C, Chollet P, Llory JF, Letourneau Y, Coudert B, Bertheaut-Cvitkovic F, Larregain-Fournier D, Le Rol A, et al. Phase III multicenter randomized trial of oxaliplatin added to chronomodulated fluorouracil-leucovorin as firstline treatment of metastatic colorectal cancer. J Clin Oncol. 2000; 18:136-47.

8. Douillard JY, Cunningham D, Roth AD, Navarro M, James RD, Karasek P, Jandik P, Iveson T, Carmichael J, Alakl M, Gruia G, Awad L, Rougier P. Irinotecan combined with fluorouracil compared with fluorouracil alone as first-line treatment for metastatic colorectal cancer: a multicentrerandomised trial. Lancet. 2000; 355:1041-7.

9. Cassidy J, Clarke S, Díaz-Rubio E, Scheithauer W, Figer A, Wong R, Koski S, Lichinitser M, Yang TS, Rivera F, Couture F, Sirzén F, Saltz L. Randomized phase III study of capecitabine plus oxaliplatin compared with fluorouracil/ folinic acid plus oxaliplatin as first-line therapy for metastatic colorectal cancer. J Clin Oncol. 2008; 26:2006-12.

10. Van Cutsem E, Köhne CH, Láng I, Folprecht G, Nowacki MP, Cascinu S, Shchepotin I, Maurel J, Cunningham D,
Tejpar S, Schlichting M, Zubel A, Celik I, et al. Cetuximab plus irinotecan, fluorouracil, and leucovorin as first-line treatment for metastatic colorectal cancer: updated analysis of overall survival according to tumor KRAS and BRAF mutation status. J Clin Oncol. 2011; 29:2011-19.

11. Bokemeyer C, Bondarenko I, Hartmann JT, de Braud F, Schuch G, Zubel A, Celik I, Schlichting M, Koralewski P. Efficacy according to biomarker status of cetuximab plus FOLFOX-4 as first-line treatment for metastatic colorectal cancer: the OPUS study. Ann Oncol. 2011; 22:1535-46.

12. Douillard JY, Siena S, Cassidy J, Tabernero J, Burkes R, Barugel M, Humblet Y, Bodoky G, Cunningham D, Jassem J, Rivera F, Kocákova I, Ruff P, et al. Randomized, phase III trial of panitumumab with infusional fluorouracil, leucovorin, and oxaliplatin (FOLFOX4) versus FOLFOX4 alone as first-line treatment in patients with previously untreated metastatic colorectal cancer: the PRIME study. J Clin Oncol. 2010; 28:4697-705.

13. Saltz LB, Clarke S, Díaz-Rubio E, Scheithauer W, Figer A, Wong R, Koski S, Lichinitser M, Yang TS, Rivera F, Couture F, Sirzén F, Cassidy J. Bevacizumab in combination with oxaliplatin-based chemotherapy as first-line therapy in metastatic colorectal cancer: a randomized phase III study. J Clin Oncol. 2008; 26:2013-19.

14. Kabbinavar F, Hurwitz HI, Fehrenbacher L, Meropol NJ, Novotny WF, Lieberman G, Griffing S, Bergsland E. Phase II, randomized trial comparing bevacizumab plus fluorouracil (FU)/leucovorin (LV) with FU/LV alone in patients with metastatic colorectal cancer. J Clin Oncol. 2003; 21:60-5.

15. Hurwitz H, Fehrenbacher L, Novotny W, Cartwright T, Hainsworth J, Heim W, Berlin J, Baron A, Griffing S, Holmgren E, Ferrara N, Fyfe G, Rogers B, et al. Bevacizumab plus irinotecan, fluorouracil, and leucovorin for metastatic colorectal cancer. N Engl J Med. 2004; 350:2335-42.

16. Kabbinavar FF, Schulz J, McCleod M, Patel T, Hamm JT, Hecht JR, Mass R, Perrou B, Nelson B, Novotny WF. Addition of bevacizumab to bolus fluorouracil and leucovorin in first-line metastatic colorectal cancer: results of a randomized phase II trial. J Clin Oncol. 2005; 23:3697-705.

17. Guan ZZ, Xu JM, Luo RC, Feng FY, Wang LW, Shen L, Yu SY, Ba Y, Liang J, Wang D, Qin SK, Wang JJ, He J, et al. Efficacy and safety of bevacizumab plus chemotherapy in Chinese patients with metastatic colorectal cancer: a randomized phase III ARTIST trial. Chin J Cancer. 2011; 30:682-9.

18. Tebbutt NC, Wilson K, Gebski VJ, Cummins MM, Zannino D, van Hazel GA, Robinson B, Broad A, Ganju V, Ackland SP, Forgeson G, Cunningham D, Saunders MP, et al. Capecitabine, bevacizumab, and mitomycin in first-line treatment of metastatic colorectal cancer: results of the AustralasianGastrointestinal Trials Group Randomized Phase III MAX Study. J Clin Oncol. 2010; 28:3191-8. 
19. Cunningham D, Lang I, Marcuello E, Lorusso V, Ocvirk J, Shin DB, Jonker D, Osborne S, Andre N, Waterkamp D, Saunders MP, AVEX study investigators. AVEX study investigators.Bevacizumab plus capecitabine versus capecitabine alone in elderly patients with previously untreatedmetastatic colorectal cancer (AVEX): an openlabel, randomised phase 3 trial. Lancet Oncol. 2013; 14:1077-85.

20. Ku GY, Haaland BA, de Lima Lopes G Jr. Cetuximab in the first-line treatment of K-ras wild-type metastatic colorectal cancer: the choice and schedule of fluoropyrimidine matters. Cancer Chemother Pharmacol. 2012; 70:231-8.

21. Stathopoulos GP, Batziou C, Trafalis D, Koutantos J, Batzios S, Stathopoulos J, Legakis J, Armakolas A. Treatment of colorectal cancer with and without bevacizumab: a phase III study. Oncology. 2010; 78:376-81.

22. Passardi A, Nanni O, Tassinari D, Turci D, Cavanna L, Fontana A, Ruscelli S, Mucciarini C, Lorusso V, Ragazzini A, Frassineti GL, Amadori D. Effectiveness of bevacizumab added to standard chemotherapy in metastatic colorectal cancer: final results for first-line treatment from the ITACa randomized clinical trial. Ann Oncol. 2015; 26:1201-7.

23. Welch S, Spithoff K, Rumble RB, Maroun J, Gastrointestinal Cancer Disease Site Group. Bevacizumab combined with chemotherapy for patients with advanced colorectal cancer: a systematic review. Ann Oncol. 2010; 21:1152-62.

24. Zhang G, Zhou X, Lin C. Efficacy of chemotherapy plus bevacizumab as first-line therapy in patients with metastatic colorectal cancer: a meta-analysis and up-date. Int J Clin Exp Med. 2015; 8:1434-45.

25. Hurwitz HI, Tebbutt NC, Kabbinavar F, Giantonio BJ, Guan ZZ, Mitchell L, Waterkamp D, Tabernero J. Efficacy and safety of bevacizumab in metastatic colorectal cancer: pooled analysis from seven randomized controlled trials. Oncologist. 2013; 18:1004-12

26. Macedo LT, da Costa Lima AB, Sasse AD. Addition of bevacizumab to first-line chemotherapy in advanced colorectal cancer: a systematic review and meta-analysis, with emphasis on chemotherapy subgroups. BMC Cancer. 2012; 12:89.

27. Lv C, Wu S, Zheng D, Wu Y, Yao D, Yu X. The efficacy of additional bevacizumab to cytotoxic chemotherapy regimens for the treatment of colorectal cancer: an updated meta-analysis for randomized trials. Cancer Biother Radiopharm. 2013; 28:501-9.

28. Chen YX, Yang Q, Kuang JJ, Chen SY, Wei Y, Jiang ZM, Xie DR. Efficacy of adding bevacizumab in the first-line chemotherapy of metastatic colorectal cancer: evidence from seven randomized clinical trials. Gastroenterol Res Pract. 2014; 2014:594930.

29. Ilic I, Jankovic S, Ilic M. Bevacizumabcombined with chemotherapy improves survival for patients with metastatic colorectal cancer: evidence from metaanalysis. PLoS One. 2016; 11:e0161912.

30. Moehler M, Sprinzl MF, Abdelfattah M, Schimanski CC, Adami B, Godderz W, Majer K, Flieger D, Teufel A, Siebler J, Hoehler T, Galle PR, Kanzler S. Capecitabine and irinotecan with and without bevacizumab for advanced colorectal cancer patients. World J Gastroenterol. 2009; 15:449-56.

31. Giantonio BJ, Catalano PJ, Meropol NJ, O'Dwyer PJ, Mitchell EP, Alberts SR, Schwartz MA, Benson AB 3rd, Eastern Cooperative Oncology Group Study E3200. Bevacizumab in combination with oxaliplatin, fluorouracil, and leucovorin (FOLFOX4) for previously treated metastatic colorectal cancer: results from the Eastern Cooperative Oncology Group Study E3200. J Clin Oncol. 2007; 25:1539-44.

32. Panic N, Leoncini E, de Belvis G, Ricciardi W, Boccia S. Evaluation of the endorsement of the preferred reporting items for systematic reviews and meta-analysis (PRISMA) statement on the quality of published systematic review and meta-analyses. PLoS One. 2013; 8:e83138.

33. Sterne JA, Sutton AJ, Ioannidis JP, Terrin N, Jones DR, Lau J, Carpenter J, Rücker G, Harbord RM, Schmid CH, Tetzlaff J, Deeks JJ, Peters J, et al. Recommendations for examining and interpreting funnel plot asymmetry in meta-analyses of randomised controlled trials. BMJ. 2011; 343:d4002. 